Sir: I read with interest Duncan \& Taylor's article (Psychiatric Bulletin, 20, 599-601) comparing the use of chlormethiazole and chlordiazepoxide in alcohol detoxification. The authors explore the historical, geographical, research and clinical reasons for the relative popularity of these two drugs. I suspect, however, that there may be another more practical reason for the continued popularity for chlormethiazole especially within the general hospital setting. Although the British National Formulary does indicate the use of chlordiazepoxide (and other benzodiazepines) in alcohol detoxification it is only in the case of chlormethiazole that a typical starting dosage together with a daily reducing regime is clearly set out. If, as the authors suggest, chlordiazepoxide is the preferred choice then perhaps clearer guidelines on dosage schedules would be helpful to non-specialist colleagues.

Hugh WILliams, UMDS, Guy's Hospital, London SE1 INP

\section{Increasing staff safety}

Sir: Parkham \& Bixby (Psychiatric Bulletin, 1996, 20, 72-74) correctly identify that researchers interviewing psychiatric patients in the community are at risk of violence and that this issue requires attention.

They note the need to have systems in place to respond quickly should a researcher fail to return to base at their allotted time. They also request that training in the prevention and management of violence be offered to interviewers. However, they do not address the issue of what type of training is appropriate for community interviewers - many of whom will have little or no clinical experience of people with mental health problems.

Staff safety requires attention to the following areas: (1) Safe systems of working - access to reports, case notes and personal contact with key staff before undertaking community visits. When patients are well, even the most violent past histories can be played down or forgotten (Blom-Cooper et al, 1995); (2) Appropriate training for interviewers. This should take into account their experience, concentrating on prevention and addressing their needs as individuals working alone in the community. Regular refreshers are essential; (3) Reporting of all violent incidents immediately. Physical violence is often preceded by verbal aggression. If this is played down another member of staff may be put at risk.

As Soloff (1983) stated, 'Violence is endemic in the mental health treatment setting and constitutes a real if unacknowledged occupational hazard'. This should be recognised by researchers and their supervisors.

BLOM-COOPER, L., HALLY, H. \& MURPHY, E. (1995) The Falling Shadow: One Patient's Mental Health Care, 1978-1993. London: Duckworth.

SolofF, P. H. (1983) Seclusion and restraint. In Assaults Within Psychiatric Facilities (eds J. R. Lion \& W. J. Reid), pp. 241-264. Orlando: Grune and Stratton.

RICHARD A. POWELL, Department of Mental Health, University of Exeter, Wonford House Hospital, Dryden Road, Exeter EX2 5AF; BRIAN KIDD, Central Scotland Health Care Trust, Bell Sdyke Hospital, Old Denney Road, Larbart, Stirling SK5 4SF

\section{Fundholding and fragmentation of care}

Sir: Lelliott \& Audini (Psychiatric Bulletin, 20, 641-642) describe difficulties related to fundholding and the care of the mentally ill. They do not address a common problem relevant to fundholding. Fundholders (often those practising on borders of two psychiatric catchment areas) may purchase psychiatric services for patients in one catchment area from a provider in the adjacent catchment area. They can only purchase out-patient and community services (day hospitals from next April); those requiring admission subsequently are expected to go to their local catchment area hospital. This clearly leads to fragmentation of care - so much for continuity of care. Moreover, the provider units in adjacent areas are likely to have weaker links with social services and voluntary agencies in the patients' catchment area.

These experiences are clearly inconsistent with Governmental policies of care in the community, care programme approach and integration of services. Central directive is needed to ensure that such fragmentation in service delivery is avoided for patients who can least advocate their concerns.

AJIT SHAH; TAMAL DE, Hounslow and Spelthorne NHS Trust, Twickenham Road, Isleworth TW7 GAF

\section{'Unexpected' deaths in psychiatry}

Sir: Recently, I have acted as a member of a panel looking at the events surrounding a suicide which occurred in a patient recently discharged from our unit. This is in accordance with our trust's 'Unexpected Deaths Protocol'. While I strongly support such investigation, which enables us to learn lessons from each suicide as they occur and sometimes to help those involved 